\title{
Development of Thermo-Physiologically
}

\section{Comfortable Knit Structure for Sports Application}

\author{
Hafiz Shehbaz Ahmad, Hafsa Jamshaid \\ Department of Knitting, Faculty of Textile Engineering, National Textile University, Pakistan
}

Corresponding Author: Hafsa Jamshaid, hrntu@hotmail.com

\begin{abstract}
This comparative study was done to study modal fiber as an ecofriendly alternative of cotton fiber in polyester-cotton (PC) fabrics. Clothing serves as a barrier between environment and human body, thus providing the thermo-physiological comfort by controlling the transportation of moisture and heat from body to external environment. Thermo-physiological comfort is an important sportswear criterion in terms of sportsmen's comfort and performance. In this study, heat and mass transfer of active sportswear were evaluated. Thermal properties were measured by sweating guard hot plate, air permeability by air permeability tester and sweat response by moisture management tester. It was found that fabric with modal on face and micro polyester on back showed best transmission properties with good pilling resistance.
\end{abstract}

\author{
ARTICLE HISTORY \\ Received: 11.07.2018 \\ Accepted: 13.03.2019
}

\section{KEYWORDS}

Plaited knit, Modal, Eco friendly, Air permeability, Thermal resistance, Sportswear

\section{INTRODUCTION}

A new important arena is sports textiles, which involves new product development for imparting the functional characteristics. Knitted fabrics are highly suitable for next to the skin wear as, it acquires high extensibility on low loading conditions which allows it to fit snugly and without discomfort on any form on which it is pulled. Increasing demand of apparel application in sportswear has opened new horizons for technological innovations.

Clothing considered as the second skin should serve as an effective transporter of sweat and barrier of heat to maintain the thermal equilibrium. The clothing comfort depends upon the moisture transfer properties, behaviour against low mechanical stress and heat of the fabrics [1]. Moisture management is crucial for thermo-physiological comfort [2]. For thermo-physiological comfort it is required to release sweat immediately from the body to the environment to reduce the skin humidity. It is very important that body should keep temperature and moisture balance according to different environmental conditions [3]. To make a fabric comfortable for wearer, it should contain two important properties, absorption of perspiration and transfer of absorbed moisture to the environment. Moisture transport in textile materials directly affects the performance of end product [4].

To cite this article: Ahmad, H.S., Jamshaid, H. 2019. Development of thermo-physiologically comfortable knit structure for sports application. Tekstil ve Konfeksiyon, 29(2), 105-112.
Comfort properties are primarily determined by chosen fibers, fabric surface roughness, and fabric structure especially thickness and porosity [5]. The main characteristics of a functional knitted structure to be used in next to skin applications are concerned with the existence of two different fabric layers identified as the separation and the absorption layers. The separation layer is usually composed of synthetic fibers and is the inside layer of the fabric (next to skin) responsible for transferring the sweat to the outer layer by wicking. The absorption layer composed of hydrophilic fiber is the outside layer responsible for absorbing and evaporating the liquid sweat $[6,7]$.

Natural fibers are considered suitable for low activity levels, synthetic fibers are better suited for high activity levels. However, no single fiber or different fiber blends can ensure ideal clothing suitable for varied applications. Cotton remains by far the most important natural fiber of the $20^{\text {th }}$ century. Cotton is a cellulosic fiber. It is characterized by comfortable soft handle and hygiene properties. Additionally, cotton fiber has good water vapor and air permeability, and hence is recommended for summer garments, but it is not a preferred choice as next to skin layer due to skin clinginess and chill feel when wet. Also, 
cotton fabrics are slow drying particularly in the conditions of high liquid sweat generation [4-7]. In different variety of crops, cotton is considered as most thirsty crop which leads to destruction of eco system in terms of fresh water across the globe. Cotton fiber is cultivated on a sustainable source yet production of its one $\mathrm{kg}$ fiber requires more than $20 \mathrm{~K}$ liters of water. It accounts for $11 \%$ sale of pesticides as well as $24 \%$ sales of insecticides. Around $2.4 \%$ area of cultivated fields is cultivated by cotton, though it is held responsible for destruction of eco-systems [8, 9]. One of the most commonly used blend in apparel sector is polyester-cotton (PC). The blending of polyester and cotton is widely practiced in the textile industry to enhance the crease resistance, strength, easy care and comfort properties [10]. The consumers now a days are more demanding in terms of comfort requirement, additionally there is an increasing demand for eco-friendly products due to rise in awareness.

Modal fiber is a cellulose fiber made up of wood pulp. Modal is a generic name for a modified viscose rayon fiber. It is emerged as sustainable material. University of Utrecht in Netherland came to conclusion that with modal, the toxic load on fresh water and soil is 100 times less as compared to cotton and their cultivation needs $10-20$ times less water in contrast to cotton [11]. It has soft handle, shiny nature and silky feel than mercerized cotton. Fabrics made from it are shrinkage resistant [12]. It is more hygroscopic in nature than cotton with excellent abrasion resistance. Fiber hygroscopicity significantly affects the water absorbance and water transfer properties. Fabric comfort is directly dependent upon water absorption, desorption and diffusion properties of textile material $[13,14]$. The hygroscopicity of modal fiber is $50 \%$ higher than cotton and is more water absorbent than that of cotton. The drying ability of modal fiber is also higher than cotton [15]. Modal fabric has overal better properties like pilling, ultraviolet protection factor (UPF) rating than cotton fabric [16, 17]. Polyester fiber has low moisture absorption and hence its easy-care properties are recommended in next to skin fabrics for active wear. The polyester fabric will absorb and wick less water. In order to overcome these limitations, micro-fibers were introduced to improve the polyester wick-ability, and thereby drying the material quickly. Microfibers are also ideal for UV protection [18]. Blends of microfibers with natural fibers are found to improve softness, drapability, dimensional stability and production speeds in knitted fabrics [15].

It has been reported that fiber type and fabric structure play a vital role in determination of comfort properties of fabrics $[1,2,18]$. Literature shows that, yarn [19] and fabric structural parameters are important in determining the fabrics moisture management properties [20].

For moisture management, double layered fabrics with different combination of yarn on outer and inner layer of the fabric have been studied by Petrusic et al. and Supuren et al $[21,22]$. They also made plaited knit fabric with the combination of natural fiber cotton on outer side and synthetic fiber polyester, polypropylene and nylon in inner side [22]. But their moisture management properties are not as high as required in high physical activities. Another problem with these fabrics is their low moisture spreading and evaporation speed. Gupta et al. [23] studied about the heat and moisture transport in single jersey plaited fabrics. They studied different single jersey plaited fabrics made from different yarns. Each yarn had different blend ratios, the study concluded that heat transport, moisture transport and air permeability are all contributing wearer's comfort. Behera et al [22] investigated bi-layered knitted fabrics with polypropylene inner and cotton outer were seen to provide better comfort, ideal for sportswear.

A study of literature published, suggests that the main focus of researchers was on constructional variables of fabric, yarn and fibers over differently knitted structures such as rib, interlock and single jersey. The yarn twist and fineness have no prominent effect on the moisture management properties of single jersey knitted fabric. Type of material also affect significantly on the moisture management properties of knitted fabric [24-26]. There are very few studies with focus over comfort properties of plaited structured single jersey fabric with back and face layers. Additionally, no detailed study was conducted regarding thermo-physiological properties such as moisture management, drying capabilities of hydrophilic and hydrophobic plaited structures, moisture and heat transfer properties.

The basic aim of this study was to investigate the plaited knitted fabrics made from modal and polyester/ micropolyester yarn as an alternative to cotton and polyester/micro-polyester in terms of thermo-physiological properties. In this study, different combinations of hydrophilic and hydrophobic yarns were used to improve the transmission properties i.e air, thermal and moisture of plaited knitted fabric. Effect of basic structural parameters i.e areal density and thickness, on fabric air permeability, thermal properties and liquid moisture transport properties were also studied. For this purpose, single jersey plaited knitted fabrics of same stitch length and same linear density were produced, two hydrophilic yarns $(100 \%$ cotton and $100 \%$ modal) were used on outer side (face/top/front) and hydrophobic yarn (polyester and Micro-polyester) were used in inner side (next to skin/back/bottom) of the plaited knit fabric. The term plating refers to formation of single loop from two threads in such a way that one thread lies at the fabric face. Serviceability of fabric i.e. pilling of fabric was also checked as polyester is used in present study -and it is more prone to pilling. As sport wear are active wear so effect of pilling is also characterized.

\section{EXPERIMENTAL}

\subsection{Materials}

The materials used in this study were cotton yarn, modal yarn, polyester and micro-polyester. Elastomeric/spandex yarn (Lycra ${ }^{\circledR}$ name given by DuPont) in alternate course was also used to improve the stability and comfort properties of prepared structures. Combed Cotton yarn (C) of linear density 14.77 Tex (40s) with hairiness index 5.50 , modal yarn (M) of 14.77 Tex (40s) with hairiness index 5.10, polyester (PET) and micro polyester (MPET) continuous filament yarns of 8.33 Tex (48f) and 8.33 Tex (144f) respectively were used for the knitted sample preparation. Spandex yarn linear density was 8.33 Tex (20 Denier).

Four samples of single jersey plaited fabrics were knitted with cotton and modal yarns in the face/top and polyester, micro-polyester filament yarns in the back/bottom layer as per the details given in Table 1. 
Table 1. Parameters of developed samples

\begin{tabular}{crccccc}
\hline $\begin{array}{c}\text { Sample } \\
\text { code }\end{array}$ & \multicolumn{2}{c}{ Yarn type } & \multicolumn{2}{c}{ Yarn linear density (tex) } & Composition & $\begin{array}{c}\text { Resultant yarn linear } \\
\text { density (tex) }\end{array}$ \\
\hline & Top & Bottom & Top & Bottom & $\%$ & 23.1 \\
CPET & C & PET & 14.77 & 8.33 & $62 / 33 / 5$ C/PET/Spandex & 23.1 \\
CMPET & C & MPET & 14.77 & 8.33 & $62 / 33 / 5$ C/MPET/Spandex & 23.1 \\
MPET & M & PET & 14.77 & 8.33 & $62 / 33 / 5$ M/PET/Spandex & 23.1 \\
MMPET & M & MPET & 14.77 & 8.33 & $62 / 33 / 5$ M/MPET/Spandex & \\
\hline
\end{tabular}

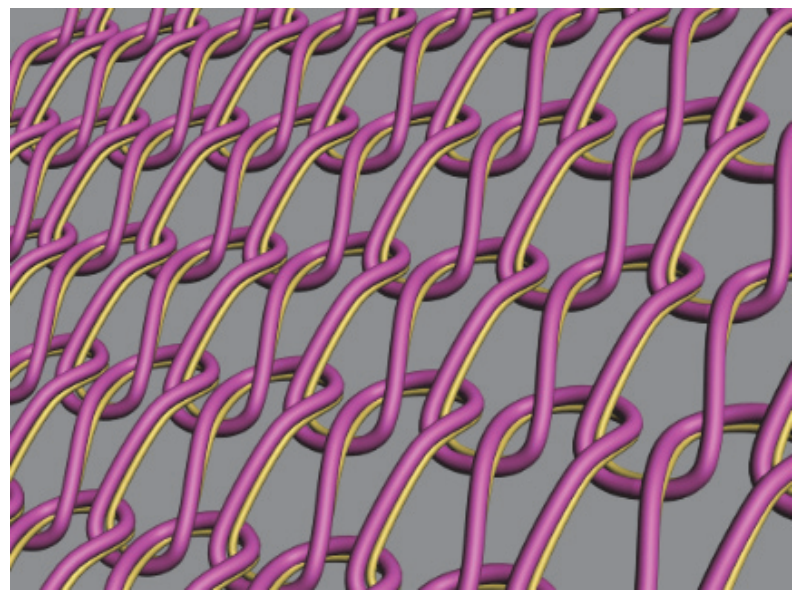

(a) Face/Top

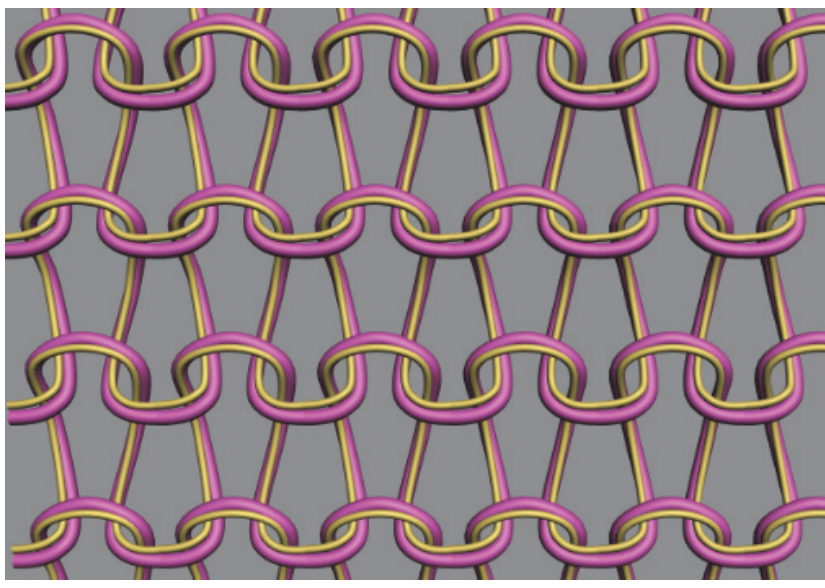

(b) Back/Bottom

Figure 1. Schematic diagram of (a) face/top and (b) back/bottom layers of plaited knitted fabrics (without inlay yarn)

These yarns were knitted on a single jersey circular knitting machine of Mayer \&Cie (Germany) S4-3.2II with diameter of 34" and E24. All the fabric parameters, courses per $\mathrm{cm}$ (CPC), wales per cm (WPC), stich length (SL), stitch density (SD), areal density (gram per square meter) and thickness are measured as per ASTM standards. Stitch length 0.3 $\pm 0.05 \mathrm{~cm}$ is maintained in all fabrics.

Fabric specifications of four types of plaited fabric samples are given in Table 2 .

\subsection{Testing}

\subsubsection{Air permeability}

Air permeability of the fabrics was measured on SDL Atlas Air Permeability Tester M021A as per ASTM-D737. Air permeability was used to measure the rate of air flow perpendicular through the fabric at the temperature of $20 \pm 2$
${ }^{\circ} \mathrm{C}$, relative humidity $65 \pm 4 \%$ with area of fabric $20 \mathrm{~cm}^{2}$ and air pressure of $100 \mathrm{~Pa}$. For every sample, 10 measurements were done and the mean and standard deviation were calculated. All the measurements were recorded under standard atmospheric conditions.

\subsubsection{Sweating guard hot plate}

The sweating guarded hot plate, which is often referred to as the "Skin Model", was used to measure the thermal resistance, according to standard method ISO 11092 on SDL M259B. For each sample, three measurements were taken, and the mean and standard deviation were calculated. All the measurements were recorded under standard atmospheric conditions. Thermal resistance has an inverse relation with thermal conductivity. Thermal resistance is the opposition to flow of heat energy. Thermal conductivity $(\lambda)$ is calculated by using following equation (1):

Table 2. Structural properties of the fabrics

\begin{tabular}{|c|c|c|c|c|c|}
\hline Sample code & CPC & WPC & $\begin{array}{l}\text { Stitch Density } \\
\left(\text { stitches } / \mathrm{cm}^{2}\right)\end{array}$ & $\begin{array}{c}\text { Mass per unit area } \\
\left(\mathrm{g} / \mathrm{m}^{2}\right)\end{array}$ & $\begin{array}{l}\text { Thickness } \\
\text { (mm) }\end{array}$ \\
\hline CPET & $25 \pm 1$ & $19 \pm 1$ & 496 & $349 \pm 10.3$ & $0.76 \pm 0.02$ \\
\hline CMPET & $24 \pm 1$ & $17 \pm 1$ & 402 & $293 \pm 11.2$ & $0.78 \pm 0.02$ \\
\hline MPET & $25 \pm 1$ & $18 \pm 1$ & 449 & $336 \pm 9.2$ & $0.78 \pm 0.02$ \\
\hline MMPET & $24 \pm 1$ & $16 \pm 1$ & 413 & $283 \pm 10.9$ & $0.8 \pm 0.02$ \\
\hline
\end{tabular}


$\lambda=t / r(W / m K)$

where, $(t)$ is thickness and $(r)$ is thermal resistance [27].

\subsubsection{Moisture management test}

Moisture management of fabrics was measured on SDL Atlas Moisture Management Tester M-290 according to standard AATCC 195-2009. Sweat response was measured by water absorption, specific flow rates and drying time. This test measures the spreading speed of water on top and bottom surfaces, its absorption and then evaluates the data to give final index $\%$ of liquid transportation in fabric. The overall moisture management capacity (OMMC) of textile material is calculated by on the bases of three measuring attributes which are moisture absorption rate on bottom surface $\left(A R_{B}\right)$, one-way liquid transport capacity ( $R$ and maximum spreading speed of liquid moisture on bottom surface $\left(\mathrm{SS}_{\mathrm{B}}\right)$. These all attributes are combined the form of below formula,

OMMC $=C_{1}{ }^{*} A R_{B}+C_{2}{ }^{*} R+C_{3}{ }^{*} S_{B}$

where, $C_{1}$ is weighting value for bottom absorption rate (ARB), $C_{2}$ is weighting value for one-way transport capacity $(R)$ and $C_{3}$ is weighting value for bottom spreading speed (SS $S_{B}$. While $C_{1}, C_{2}$ and $C_{3}$ are adjusted depending upon the relative importance of above three indexes and mainly depends upon the type of fabric and its end use. In general, the values used in the development if MMT software are $\mathrm{C}_{1}=0.25, \mathrm{C}_{2}=0.5$ and $\mathrm{C}_{3}=0.25$ which is based on human perception studies [28].

Conditioned test specimens were placed between the top and bottom concentric pins in such a way that the skin touch side of fabric was placed as top side and touches the top pins of moisture management tester. The results obtained from this test are based on water resistance, water repellency and water absorption characteristics of the fabric structure including fabric's geometric and internal structure and the wicking characteristics of its fibers and yarns.

For each sample, three measurements were taken and the mean $(m)$ and standard deviation $(r)$ were calculated. All the measurements were recorded under standard atmospheric conditions.

\subsubsection{Pilling}

Pilling in fabric from both sides were measured by $\mathrm{ICl}^{\circledR}$ Pilling Box Test with international standard of pilling (BS5811).

For each sample, three measurements were taken and the mean and standard deviation were calculated. All the measurements were recorded under standard atmospheric conditions.

\subsection{Statistical Analysis of Results}

Data were expressed as mean \pm standard deviation. Analysis of Variance (ANOVA) test was applied to determine the significance of the variables under study with the help of Minitab. The ANOVA is best employed where more than two populations are compared. In the tables, DF, SS, and MS, represent the sum of squares, mean squares and degree of freedom. Due to the $95 \%$ confidence interval, the parameters with $p<0.05$ values indicate that the effect of that parameter on the given experimental layout is statistically significant. The effect of fiber type on the thermo-physiological comfort properties were investigated values less than 0.05 were considered as statistically significant. The goodness of fit (coefficient of determination, $R^{2}$ ), were also calculated.

\section{RESULTS AND DISCUSSIONS}

\subsection{Physical Properties}

The areal density of knitted fabrics depends on yarn fineness, knit structure and dimensional properties. It can be observed that the areal density (in grams per square meter) of the fabric made from micro-denier is slightly on lower side compared to normal denier fabric, which is due to the lower stitch density as investigated by other researchers [29].

Fabric thickness depends on loop shape, knit structure, relative closeness of loops i.e. stitch density and compactness of structure. There is no significant difference in the thickness of fabrics. A slight high thickness in micro denier fabric with the same application of load is because of the air particles present in the fabric which resist further compression.

\subsection{Thermo-Physiological Comfort Properties}

\subsubsection{Air permeability}

Air permeability is that property a fabric which is often used as a parameter to evaluate and compare its 'breathability'. Regarding the comfort of fabric air permeability is an important factor.

Table 3. Air permeability of fabrics

\begin{tabular}{lc}
\hline Sample code & Air permeability $(\mathbf{m m} / \mathbf{s})$ \\
\hline CPET & 59 \\
CMPET & 55 \\
MPET & 108 \\
MMPET & 91 \\
\hline
\end{tabular}

Table 4. ANOVA response table of fiber type on air permeability properties

\begin{tabular}{llllllll}
\hline Testing & Results & DF & SS & MS & F & P & R-sq \\
\hline \multirow{2}{*}{ Air permeability } & Face material & 1 & 5325.7 & 5325.7 & 239.33 & 0 & $96.57 \%$ \\
& Back material & 1 & 314.2 & 314.2 & 14.12 & 0.005 \\
\hline
\end{tabular}


Effect of fiber type on air permeability was found to be significant ( $p$-value=0.005) as shown in Table 4 Corresponding coefficient of determination (R2) indicates the good quality of fit.

As results in Figure 2 have shown that the air permeability of the micro denier polyester fabric is on lower side than conventional polyester due to compactness, as the number of filaments in a yarn of given linear density increases, the surface area of all the fibers increases and the spaces between the fibers becomes smaller. This hinders air flow [30].

When considering the effect of fiber types, fabrics made from regenerated cellulose fiber i.e modal have the highest air permeability values. Overall, plaited knit fabric having modal and polyester has highest air permeability value, which makes it exceptionally breathable as compared to other plaited knit fabrics. Because the hairiness value modal fiber is low than cotton which allows the air to pass easily. Also, the conventional polyester fiber is less compact than micro-polyester and proved less hindrance to pass the air. Ultimately knitted fabric with modal and polyester fiber shows higher value of air permeability.
Cotton convolutions are ribbon-like twists that characterize cotton. As cotton fiber becomes mature, lumen dries and collapses resulting twisting of secondary wall. These fibers convolutions along with extra cotton yarn hairiness lead to enhancement in air resistance of the cotton samples resulting in low air permeability in comparison modal fibers as studied by other researchers [12].

\subsubsection{Thermal properties}

The most important consideration which is taken into account for thermal comfort of garments is thermal resistance which is termed as resistance offered by fabric against heat flow. Thermal resistance that is a measure for insulation value is reciprocal of thermal conductivity. Thermal conductivity represents the transfer of heat which is resultant of structural characteristics of fabric and conductivity of fibers. The results of thermal resistance measured in sweating guarded hot plate are shown in Fig. 3. Effect of fiber type on thermal properties was found to be significant $(p$-value $=0)$ as shown in Table 6 .

Table 5. Thermal properties of knitted fabric

\begin{tabular}{lcc}
\hline Sample code & $\begin{array}{c}\text { Thermal resistance } \\
\left(\mathbf{m}^{\mathbf{2}} \mathbf{K} / \mathbf{W}\right)\end{array}$ & $\begin{array}{c}\text { Thermal conductivity } \\
(\mathbf{W} / \mathbf{m K})\end{array}$ \\
\hline CPET & 0.0062 & 0.123 \\
CMPET & 0.0104 & 0.075 \\
MPET & 0.0054 & 0.145 \\
MMPET & 0.0094 & 0.085 \\
\hline
\end{tabular}

Table 6. ANOVA response table of fiber type on Thermal properties

\begin{tabular}{ccccccccc}
\hline Testing & Results & DF & SS & MS & F & P & R-sq & R-sq (adj) \\
\hline $\begin{array}{c}\text { Thermal } \\
\text { conductivity }\end{array}$ & Face material & 1 & 0.0008085 & 0.0008085 & 67.05 & 0 & \multirow{2}{*}{$98.87 \%$} & $98.62 \%$ \\
& Back material & 1 & 0.0086672 & 0.0086672 & 718.8 & 0 & & \\
\hline $\begin{array}{c}\text { Thermal } \\
\text { resistance }\end{array}$ & Face material & 1 & 0.000002341 & 0.000002341 & 25.05 & 0 & \multirow{2}{*}{$98.50 \%$} & $98.17 \%$ \\
\hline
\end{tabular}

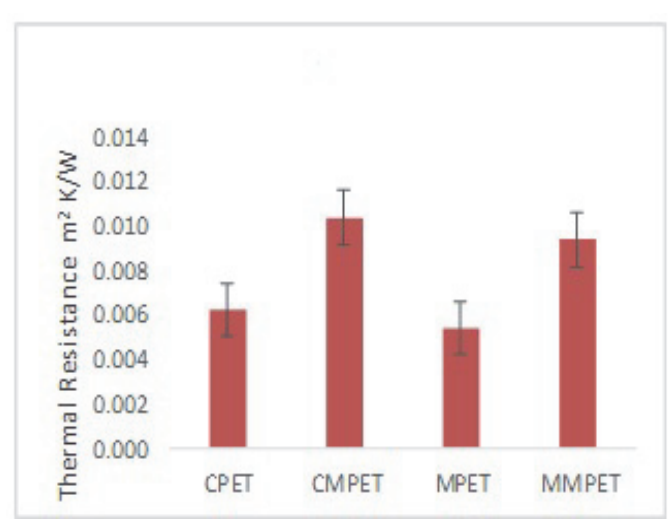

(a)

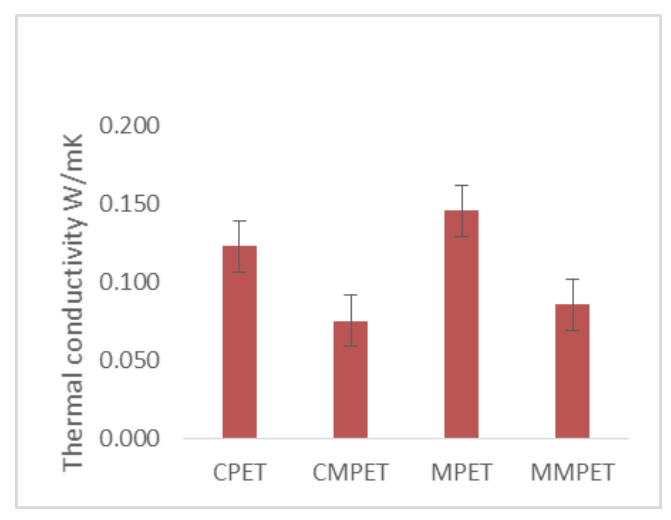

(b)

Figure 3. Thermal resistance (a) and Thermal conductivity (b) of the fabrics 
High areal density leads to more thermal resistance of CMPET and MMPET knitted fabric. Fabric structures having micro-denier yarn in it have high thermal resistance, higher the number of fibers for the same fineness more will be air pockets. Micro denier fabrics have lower thermal conductivity, high thermal resistance when compared with normal denier fabrics.

\subsubsection{Moisture management properties}

Moisture transport in textile materials resembles with wicking of water in capillaries. The capillary wicking is determined by its two fundamental properties which are effective diameter of inside face and surface energy respectively. As the diameter is small, more will be its surface energy which means water moves readily in upward direction in capillary. In textile structures, the spaces between fibers effectively form capillaries, the closer fibers are packed together in yarn, the smaller the apparent capillary diameter and more readily wicking can occur.

The results obtained from moisture management test (MMT) of plaited knit fabric, are based on the water resistance, water repellency and water absorption characteristics of the fabric structure including fabric's geometric and internal structure and the wicking characteristics of its fibers and yarns. MMT equipment gives many measurement parameters related to moisture management properties of fabrics. Among these parameters, Accumulative one-way transport-index (AOTI) and Overall Moisture management capacity (OMMC) are more important in terms of making a general evaluation liquid transport ability of fabrics. OMMC shows overall management performance of liquid moisture of fabric and the higher this value is, the better the liquid transport performance of fabric is. On the other hand, AOTI is a value that shows cumulative moisture amount difference between two surfaces of the fabric. The AOTI show the value of fabrics ability to transport water from surface to the other in a specific time. As AOTI value increases in a positive direction, the transfer of liquid from skin to environment will be easy and fast. Negative and low AOTI values show that the fabric absorbs faster and removes the liquid slowly [31].

Effect of fiber type on OMMC was found to be significant on face side as shown in Table 8 . Wetting time, absorption rate and spreading speed are linked with each other. Higher the absorption rate lower will be wetting time and lower will be spreading speed. Because a material with high absorption rate will absorb more liquid moisture and will take less time to wet the material. Ultimately its spreading speed will be reduced due to high absorption. If we compare the cotton with modal, cotton has lower moisture absorption rate than modal and will take more time to wet than modal. Similarly, if we compare polyester with cellulosic fibers i.e. cotton and modal, polyester has less absorption rate and it takes more time to wet. The possible reason behind this behavior is that the polyester is a hydrophobic fiber and have a very little moisture regain of $0.4 \%$ while cotton (hydrophilic in nature) have moisture regain of $8.5 \%$. The polyester also has poor moisture transfer properties while cellulosic fibers have moisture accumulation on top surface [32]. That's why the wetting time of polyester is high because the water is not absorbed in the polymeric structure, but it is adsorbed on surface and spreads through capillary action. On the other hand, cotton is more absorbent due to which water is absorbed in its polymeric structure and has less wetting time.

Polyester in comparison with micro-polyester shows lower absorption rate and higher wetting time due to packing coefficient of micro denier yarns is greater than that of corresponding normal denier yarns. Table 7 shows that micro-polyester has lowest absorption rate than other fibers and have highest wetting time and higher spreading speed. It is therefore expected that the average capillary size would be less in micro denier yarns. Low capillary diameter is expected to increase capillary pressure and drive the water faster into the capillaries of the yarn [23]. It is because of the reason that the wicking action of the micro-polyester is better than that of cotton due to the narrow spaces and high surface energy. Table 7 shows that the modal have high absorption rate with less wetting rate. This makes it an excellent alternative of the cotton in terms of absorbency. As modal is about $50 \%$ more hygroscopic, or water-absorbent, per unit volume than cotton, Therefore, modal characterized by more water absorbing sites and hence higher moisture regain would transfer more moisture owing to combined effect of diffusion and absorption-desorption. So, the combination of micro-polyester and modal is the combination to provide thermo-physiological comfort to its wearer. The micro polyester with high surface energy and less diameter wicks the water and transfer it to modal surface where it is quickly absorbed and spread for the evaporation. As a result, the surface of sportsman remains dry despite of his high sweating rate. The testing results of this single jersey plaited knit fabric depicts the fabric's tendency to transport the water.

Table 7. Moisture management test results

\begin{tabular}{|c|c|c|c|c|c|c|c|c|c|c|}
\hline $\begin{array}{l}\text { Sample } \\
\text { code }\end{array}$ & $\begin{array}{l}\text { Wetting } \\
\text { Time } \\
\text { Top } \\
\text { (s) }\end{array}$ & $\begin{array}{l}\text { Wetting } \\
\text { Time } \\
\text { Bottom } \\
\text { (s) }\end{array}$ & $\begin{array}{c}\text { Top } \\
\text { Absorption } \\
\text { Rate } \\
(\% / s)\end{array}$ & $\begin{array}{c}\text { Bottom } \\
\text { Absorption } \\
\text { Rate } \\
(\% / s)\end{array}$ & $\begin{array}{c}\text { Top Max } \\
\text { Wetted } \\
\text { Radius } \\
(\mathrm{mm})\end{array}$ & $\begin{array}{c}\text { Bottom Max } \\
\text { Wetted } \\
\text { Radius } \\
\text { (mm) }\end{array}$ & $\begin{array}{c}\text { Top } \\
\text { Spreading } \\
\text { Speed } \\
(\mathrm{mm} / \mathrm{s})\end{array}$ & $\begin{array}{c}\text { Bottom } \\
\text { Spreading } \\
\text { Speed } \\
(\mathrm{mm} / \mathrm{s})\end{array}$ & AOTI (\%) & OMMC \\
\hline$\overline{\mathrm{CPET}}$ & 4.64 & 4.48 & 46.91 & 32.41 & 15 & 15 & 2.192 & 2.17 & 130.68 & 0.398 \\
\hline CMPET & 4.18 & 4.12 & 49.92 & 35.37 & 15 & 18.75 & 2.53 & 2.62 & 131.81 & 0.442 \\
\hline MPET & 4.44 & 4.59 & 60.49 & 23.85 & 15 & 20 & 2.25 & 2.54 & 416.34 & 0.763 \\
\hline MMPET & 3.94 & 7.19 & 42.81 & 10.27 & 15 & 20 & 1.57 & 2.89 & 449.82 & 0.773 \\
\hline
\end{tabular}


Table 8. ANOVA response table of fiber type on OMMC

\begin{tabular}{lllllllll}
\hline Testing & Results & DF & SS & MS & F & P & R-sq & R-sq (adj) \\
\hline \multirow{2}{*}{ OMMC } & Face material & 1 & 0.37627 & 0.37627 & 526.63 & 0 & \multirow{2}{*}{$98.33 \%$} & $97.95 \%$ \\
& Back material & 1 & 0.00123 & 0.00123 & 1.72 & 0.223 & \\
\hline
\end{tabular}

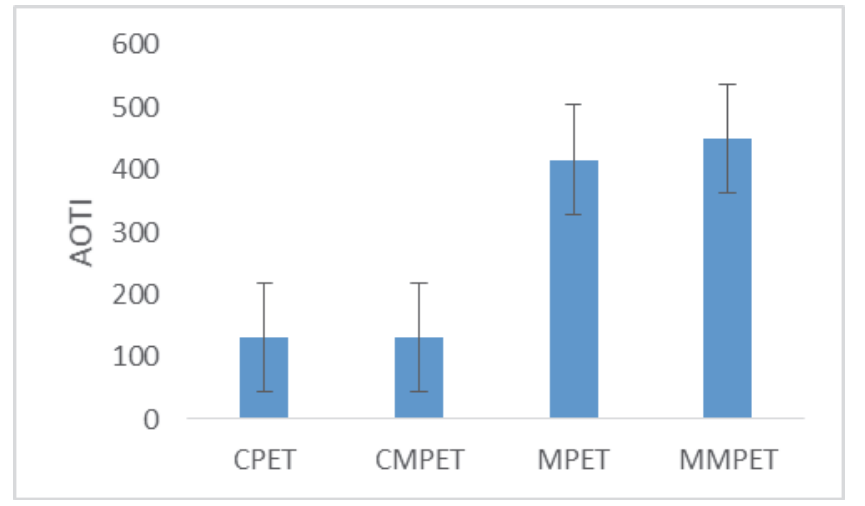

(a) AOTI

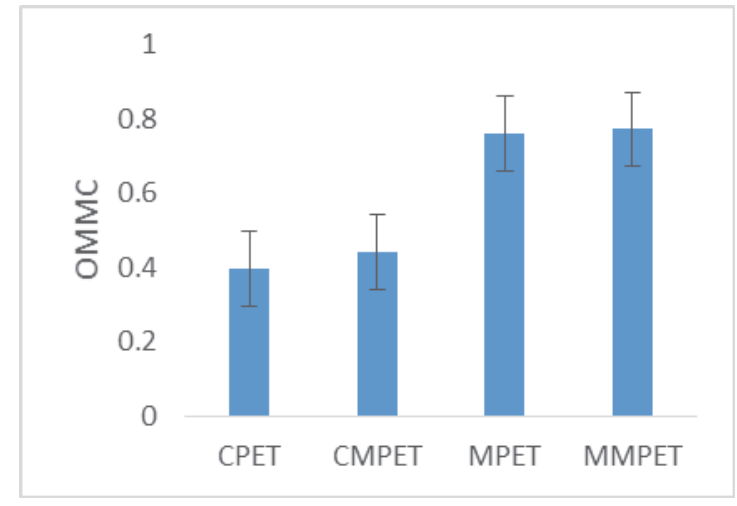

(b) OMMC

Figure 4. Moisture management results of (a) AOTI \& (b) OMMC

AOTI and OMMC results of fabrics are presented in Fig. 4(a) \& (b) respectively. According to the AOTI results, MPET and MMPET fabrics generally exhibit higher values compared to CPET and CMPET fabrics. This combination of modal and micro polyester has highest accumulative oneway transport Index (\%) among all the other structures considered in this study. The reason lies in the unique properties of micro polyester and modal. The narrow channels in the micro polyester structure reduce the wicking time and quickly transfers water from skin to outer surface where modal quickly absorbs the water and spreads it to be evaporated. OMMC values lie in the range of 0.77 . This condition shows that MPET and MMPET fabrics have high liquid moisture management capacity.

\subsection{Mechanical Properties}

\subsubsection{Pilling}

The pilling resistance of fabric is denoted by the grading as shown in Table 9 with higher grading representing better pilling resistance.

Table 9. Pilling of different fabrics

\begin{tabular}{lcc}
\hline \multirow{2}{*}{ Sample code } & \multicolumn{2}{c}{ Pilling (Grading) } \\
\cline { 2 - 3 } & Face & Back \\
\hline CPET & 4 & 3 \\
CMPET & 4 & 5 \\
MPET & 5 & 3 \\
MMPET & 5 & 5 \\
\hline
\end{tabular}

There is no significant difference in pilling resistance of fabric combinations. The plaited fabric with micro-polyester and modal showed highest resistance to pilling as micro denier yarns have less hairiness [32]. So, overall serviceability of MMPET structure is better.

\section{CONCLUSIONS}

Need of time is to use renewable and ecofriendly materials. In present study MPET and MMPET are studied as an alternative of CPET and CMPET. The results indicated that fiber type has significant effect on properties. It is concluded from this study that moisture management properties of plaited knit fabrics depend upon the material used on plating side of the fabric. More the hydrophobicity of the material, more will the wicking properties. It was found that by using a combination of modal and micro-polyester (MMPET) maximum moisture transportation was obtained. With this combination, not only moisture management but also air permeability and thermal conductivity were improved without any extra treatment. This fabric has much higher evaporation rate and low drying time. Sports clothing can be worn for different reasons. Modal single jersey fabrics are preferred alternatives for warmer climate sportswear, due to their higher air permeability and overall management properties with improved pilling properties. This combination is also good for UV protection as per already available research work. It helps to protect the sportsman from the damaging effect of sun exposure. In view of above study, the use of modal fibers with micro-polyester can be an alternative of cotton and its blends. 


\section{REFERENCES}

1. Uttam D., Mukhopadhyay A.\& Ishtiaque SM. (2016), Modelling to predict thermophysiological properties of hollow / microporous yarn fabrics, $J$. Text. Inst., Vol. 104, no. 4, pp. 407-4013.

2. Erdumlu N.\& Saricam C.( 2013), Wicking and drying properties of conventional ring- and vortex-spun cotton yarns and fabrics, J. Text. Inst., Vol. 104, no. 12, pp. 1284-1291.

3. Öner E. \& Okur A.( 2013), The effect of different knitted fabrics' structures on the moisture transport properties, J. Text. Inst., vol. 104 no. 11 , pp. 1164-1177.

4. Patil UJ., Kane CD.\& Ramesh P.(2009), Wickability behaviour of singleknit structures, J. Text. Inst., Vol. 100, no. 5, pp. 457-465.

5. Yoon H. N.\& Buckley A.(1984), Improved Comfort Polyester: Part I: Transport Properties and Thermal Comfort of Polyester/Cotton Blend Fabrics, Text. Res. J., Vol. 54, no. 5, pp. 289-298.

6. Geraldes M.J., Lubos H., Araujo M. \& Belino N.J.R. NM.(2008), Engineering Design of The Thermal Properties In Smart And Adaptive, Autex Res. J., Vol. 8, no. 1 pp. 30-34.

7. Oglakcioglu N., Celik P., Ute TB.Marmarali A. \& Kadoglu H.(2009) Thermal Comfort Properties of Angora Rabbit/Cotton Fiber Blended Knitted Fabrics, Text. Res. J., Vol. 79, no. 10, pp. 888-894.

8. Pınar D.B.\& Osman B. RE.( 2006), Prediction of Strength and Elongation Properties of Cotton / Polyester-Blended OE Rotor Yarns, Fibres Text. East Eur., Vol. 14, no. 1, pp. 18-21.

9. Bellon-Maurel V., Short M. D., Roux P.,, Schulz M., \& Peters G.M (2014), Streamlining life cycle inventory data generation in agriculture using traceability data and information and communication technologies - part I: concepts and technical basis, J. Clean. Prod., Vol. 69, pp. 6066.

10. Tausif M., Ahmad F., Hussain U., Basit A.,\& Hussain T.(2015), A comparative study of mechanical and comfort properties of bamboo viscose as an eco-friendly alternative to conventional cotton fibre in polyester blended knitted fabrics,J. Clean. Prod., Vol. 89, pp. 110-115.

11. Postle R.(2008), Dimensional Stability of Plain-Knitted Fabrics,J. Text Inst., Vol. 59, no. 2, pp. 65-67

12. Arafa A., Hassanin A. \& Moursey M.( 2016), Influence of Tencel / cotton blends on knitted fabric performance, Alexandria Eng. J., Vol. 55, no. 3 , pp. 2439-2447.

13. Gulbinienè A., Jankauskaitè V., Sacevičienè V. \& Mickus K.V.( 2007), Investigation of Water Vapour Resorption / Desorption of Textile Laminates, Mater. Sci., Vol. 13, no. 3, pp. 255-261.

14. Zhou L., Feng X.\& Li Y.( 2010), Influences of the Fibre Hygroscopicity of Connecting Yarn on the Liquid Water Transfer Property of Knitted Double-Layer Fabric, Fibres Text. East Eur., Vol.18, no. 6, pp. 72-75

15. Dipa R.(2017), Biocomposites for High-Performance Applications,ManMade Cellulose Fibre Reinforcements (MMCFR), India: Woodhead Publishing.

16. Saravanan D.( 2007), UV Protection Textile Materials, Autex Res. J., Vol. 7 , no. 1 pp. 53-62

17. Gun AD.( 2011), Dimensional , Physical and Thermal Comfort Properties of Plain Knitted Fabrics Made from Modal Viscose Yarns
Having Microfibers and Conventional Fibers, Fiber Polym., Vol. 12, no. 2, pp. 258-267.

18. Hoschke B. V. \& Hoschke B. N.( 1983), Dry Heat Transfer Characteristics of Underwear Fabrics, Text. Res. J., Vol. 53, no. 6, pp. 368-374

19. Kathleen M., Walde-Armstrong D.B.,\& Fair J.(1996), Development and Evaluation of a Prototype Athletic Girdle, Cloth Text. Res. J. Vol. 14. no. 1 , pp. 73-80.

20. Frackiewicz-Kaczmarek J., Psikuta A.,Bueno M.A., \& Rossi M. R.( 2015), Air gap thickness and contact area in undershirts with various moisture contents: influence of garment fit, fabric structure and fiber composition, Text. Res. J., Vol. 85, no. 20, pp. 2196-2207.

21. Petrusic S., Onofrei E., Bedek G., Codau C., Dupont D. \& Soulat D., (2015), Moisture management of underwear fabrics and linings of firefighter protective clothing assemblies, J. Text. Inst., Vol. 106, no. 12, pp. 1270-1281.

22. Supuren G., Oglakcioglu N., Ozdil N. \& Marmarali A. (2011), Moisture Management and Thermal Absorptivity Properties of Double-Face Knitted Fabrics, Text. Res. J., Vol. 81, no. 13, pp. 1320-1330.

23. Gupta D., Kothari V.K. \& Jhanji Y.(2014), Heat and moisture transport in single jersey plated fabrics, Indian J. Fibre Text. Res., Vol. 39, pp. 115121.

24. Özdil N., Süpüren G., Özçelik G. \&Pruchova J.(2009), A Study on the Moisture Transport Properties of the Cotton Knitted Fabrics in Single Jersey Structure, Tekstil ve Konfeksiyon, Vol.19, no. 3, pp. 218-223.

25. Özdil N., Süpüren G., Özçelik G., Farklı Materyallerden Üretilen Örme Kumaşların Çok Yönlü Nem Illetim Özellikleri/(2009), Moisture Management Properties of Fabrics Knitted with Different Materials, Tekstil Teknoloji, Vol. 14, no. 156, pp. 172-186.

26. Özdil N., Süpüren G., Özçelik G., Farklı Materyallerden Üretilen Örme Kumaşların Çok Yönlü Nem Iletim Özellikleri II/ (2009),Moisture Management Properties of Fabrics Knitted with Different Materials II, Tekstil Teknoloji, Vol, 14, no. 157, pp. 114-120.

27. Jamshaid H., Mishra R., Militky J. Novak J., 2015, "End use performance characterization of unconventional knitted fabrics", Fiber Polym., Vol. 16, no. 11, pp. 2477-2490

28. AATCC D195-12,( 2011), Standard Test Method for Liquid Moisture Management Properties of Textile Fabrics.

29. Srinivasan J., Ramakrishnan G., Mukhopadhyay S. \& Manoharan S.( 2007), A study of knitted fabrics from polyester microdenier fibres, $J$. Text. Inst., Vol. 98, no. 1, pp. 31-35.

30. Nassif G.A.A. (2012), Effect of Weave Structure and Weft Density on the Physical and Mechanical Properties of Micro polyester Woven Fabrics,J. Am.Sci ., Vol. 8, no. 8, pp. 947-952.

31. Junyan Hu., Li Y., Yeung K.W., Anthony S. W., Wong W. \&Xu W., 2005), Moisture management tester: a method to characterize fabric liquid moisture management properties, Text. Res. J., Vol. 75 , no. 1 , pp.57-62.

32. Jhanjia Y., Guptab D. \& Kotharib V.K.( 2015), Moisture management properties of plated knit structures with varying fiber types, J. Text. Inst., Vol. 106, no. 6, pp. 663-673. 